\title{
BENCH RESEARCH OF HIGH-FREQUENCY ELECTRIC WELDING OF BIOLOGICAL TISSUES*
}

\author{
G.S. MARINSKY ${ }^{1}$, A.V. CHERNETS ${ }^{1}$, V.A. TKACHENKO ${ }^{1}$, D.A. GRABOVSKY ${ }^{1}$, S.E. PODPRYATOV ${ }^{1,2}$, \\ E.G. LOPATKINA ${ }^{1}$, S.S. PODPRYATOV ${ }^{2}$, S.V. TKACHENKO ${ }^{1}$ and S.G. GICHKA ${ }^{3}$ \\ ${ }^{1}$ E.O. Paton Electric Welding Institute, NASU \\ 11 Kazimir Malevich Str., 03680, Kiev, Ukraine. E-mail: office@paton.kiev.ua \\ ${ }^{2}$ Kiev City Center of Electric Welding Surgery \\ 121 Kharkov Highway, 02091, Kiev, Ukraine. E-mail: sepodpryatov@yahoo.com \\ ${ }^{3}$ Kiev City Clinical Hospital \#1 \\ 121 Kharkov Highway, 02091, Kiev, Ukraine
}

\begin{abstract}
The paper gives a description of an all-purpose laboratory complex for investigations of biological tissue behaviour at application of high-frequency currents to them under the conditions, corresponding to welding live tissues by different algorithms. This complex allows studying the influence of various design features of the instruments and welding process parameters on the behaviour and structural changes of biological tissues. This equipment is optimal to conduct optimization of new technological procedures, parameters and software, oriented towards specific surgical procedures. Given as an example are the results of experiments on welding the walls of pig stomach and small intestine at pulsed and continuous feeding of $440 \mathrm{kHz}$ voltage under the conditions corresponding to electric welding of biological tissues. 10 Ref., 10 Figures.
\end{abstract}

Ke y w ord s : high-frequency welding, biological tissues, all-purpose testing bench, welding algorithms, biological tissue structures

Further development of technology and equipment for high-frequency welding of biological tissues, which is becoming ever wider applied in medical practice [1-7], is inseparably linked to comprehensive studies of the influence of various process parameters on behaviour and structural changes of these tissues, which form the welded joint at high-frequency (HF) current passing through them.

To conduct this research series, the authors developed a specialized complex (Figure 1), which allows studying under laboratory conditions at minimum cost the regularities of HF current passage, depending on biological tissue type, as well as behaviour of various types of tissues at HF current passage through them by the most diverse algorithms. This complex allows studying the influence of various design features and process parameters, such as, for instance, material, shape, dimensions and weight of electrodes, specific pressure at variable energy parameters of the welding process, etc., on behaviour and structural changes of biological tissues. This equipment is optimum for refining new technological procedures, parameters and

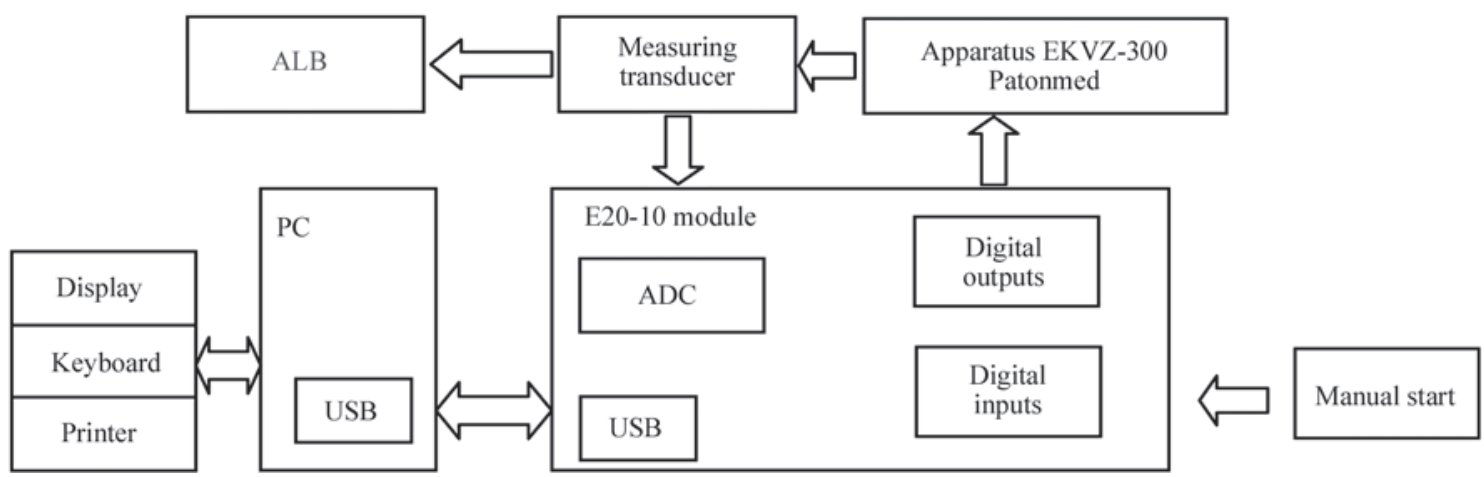

Figure 1. Functional block-diagram of research complex

\footnotetext{
${ }^{*}$ The following staff of PWI participated in the work: V.A. Vasilchenko, Yu.Z. Buryak, V.K. Serdyuk, A.M. Aleksandrov, P.G. Semenov. 


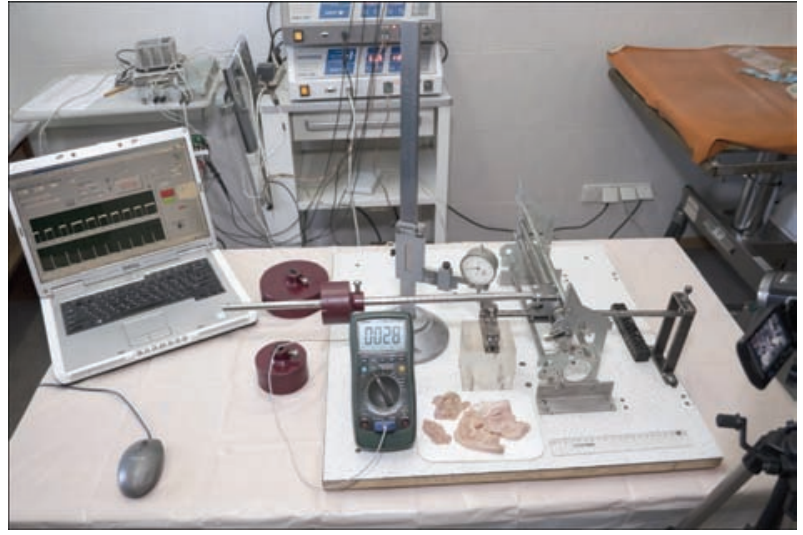

Figure 2. Appearance of all-purpose laboratory bench at operation with flat and circular electrodes

program products, oriented to specific surgical procedures.

Other research can also be performed, such as studying the impact of HF current on hydration of various types of biological tissues, and nature of tissue heating at HF current passing through them by various algorithms.

The basic element of this complex is an all-purpose laboratory bench (ALB), where the object of study (biological tissue samples) is placed (Figure 2). Bench design allows using electrodes of different configurations at adjustable and preset pressure on the tissue.

A feature of ALB is availability of replaceable electrodes (Figure 3 ) that provides extreme flexibility at performance of experiments on selection of design, geometry, materials and coatings during development and manufacture of electrosurgical instruments. It is known that pressure on the tissue is one of the most important process parameters in live tissue welding. In this research complex electrode pressure on the tissue, which is adjustable, preset and reproducible from experiment to experiment, is provided by a system of levers and standard loads within $0-160 \mathrm{~N}$.

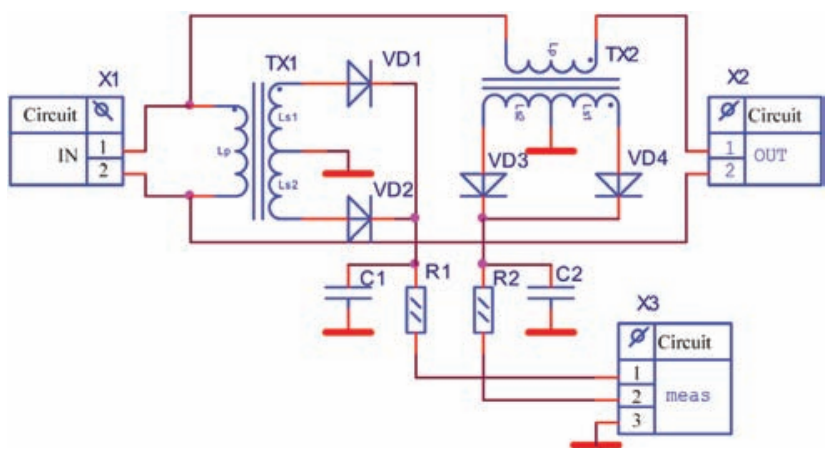

Figure 4. Elementary diagram of measuring transducer

Power source is EKVZ-300 apparatus for live tissue welding, adapted to the conditions of laboratory experiments. Its design allows issuing signals by the most diverse algorithms [8-10]. Current from the power source passes through measuring transducer module (Figure 4) which provides galvanic decoupling of power and measuring circuits. Signals of HF voltage and current are first scaled, rectified and then pass through apparatus filtering by low-frequency filter with specified parameters (the diagram shows a simplified filter). Filter setting depends on apparatus working frequency.

E20-10 module is a module of high-speed analog-digital converter with USB 2.0 interface of L-Card Company. It provides dynamic recording of current and voltage values during HF impact on live tissues. It is possible to set sampling rate and dynamic range of measured analog values, using special programs. An optimum value of the number of measurements per second is selected to achieve a compromise between the validity of the obtained data and data file size. Sampling frequency can be increased at recording of short processes. Equipment allows measurements to be performed with the frequency of up to $5 \mathrm{MHz}$. A value of about 1000 measurements per second $(1 \mathrm{KHz})$ was used in laboratory studies.

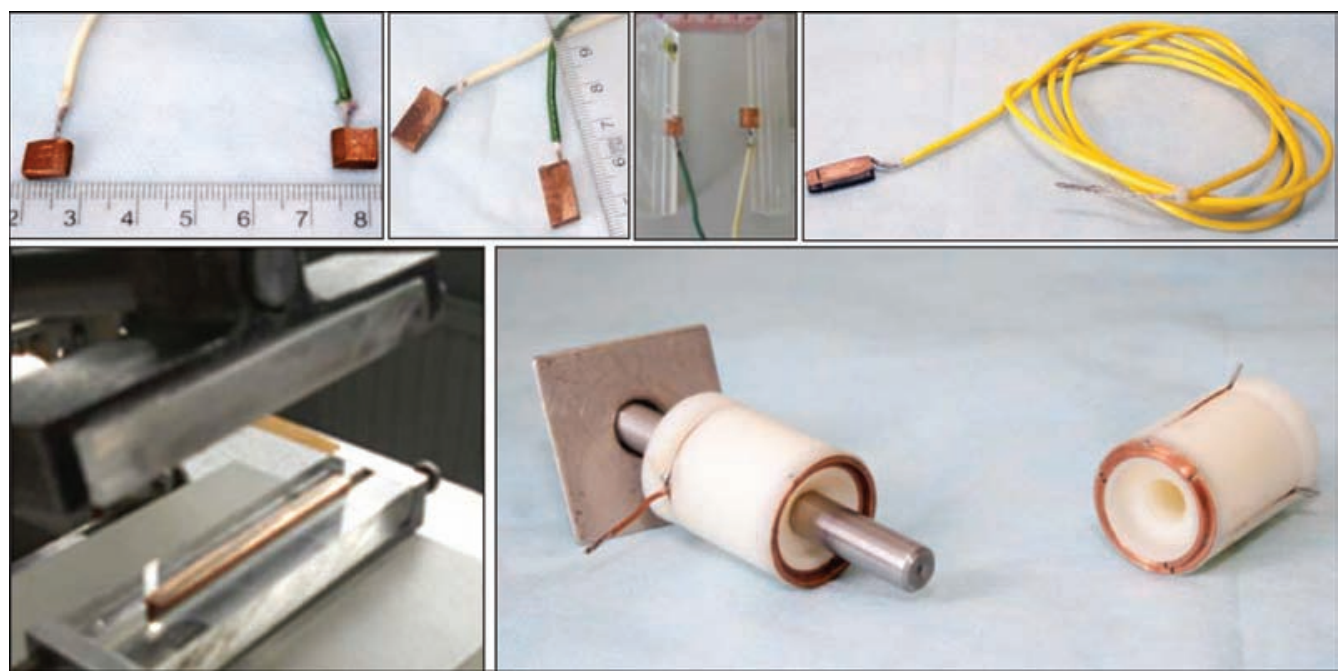

Figure 3. Electrodes of different design applied in ALB 


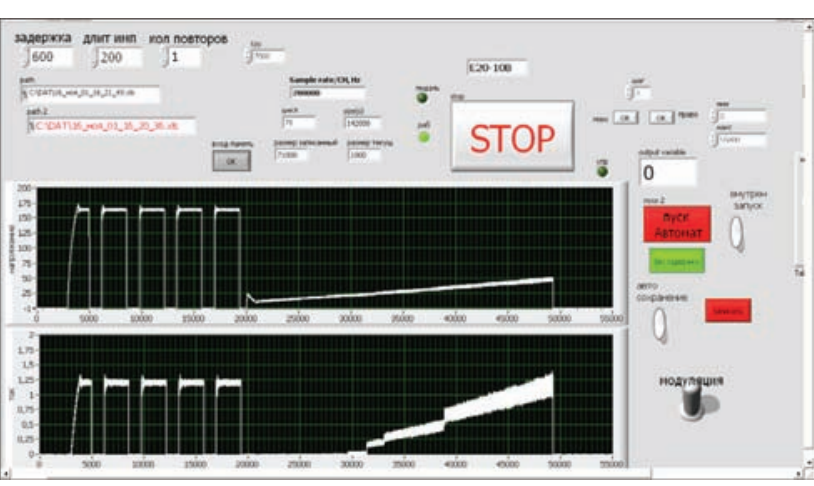

Figure 5. Appearance of the screen of recording and control program

Digital output module is installed in one case with ADC (E20-10), but functionally, it has a different purpose. This module is used to form service signals of coagulator control, signals to source switching relays, etc. Digital output module allows, if required, starting the process in the manual mode. The device (ADC E20-10) is connected to the computer via USB cable and uses standard Windows drivers.

Electrical parameters of the process were recorded by an analog-digital converter L-Card E20-10, personal computer and laboratory oscillograph Tektronix TDS 3014C. Software consists of two independent parts: program of recording and program of processing the obtained data. Programs are written in graphic programming language LabVIEW. It allows using dataflow programming, in which the execution sequence is determined by data flow. The program is based on virtual instruments supplied by L-Card Company, together with the library for ADC E20-10 and similar modules. Recording program allows maximum automation of research process, thus reducing the influence of the human factor on the results. The program, in particular, fulfills service functions. Recording module uses a special program to form a time delay before the experiment start. Controls and indicators are located on virtual instrument front panel (Figure 5). There is the capability of assigning a large number of parameters. The following pulse parameters are adjusted: pulse duration, pause duration, number of repeats, there is the capability of additionally extending recording time, setting recording mode, adjusting parameters of preliminary visualization of the process. In some cases, external start is required (from a pedal or a button on the instrument). In the automatic mode there is the capability of activating the countdown to experiment start with sound signal and time display. During recoding the data are stored in the buffer. This buffer is used at process visualization. Here, the parameters of data displaying can be assigned (Figure 6). Software module of results processing provides the required graphs or tables for the

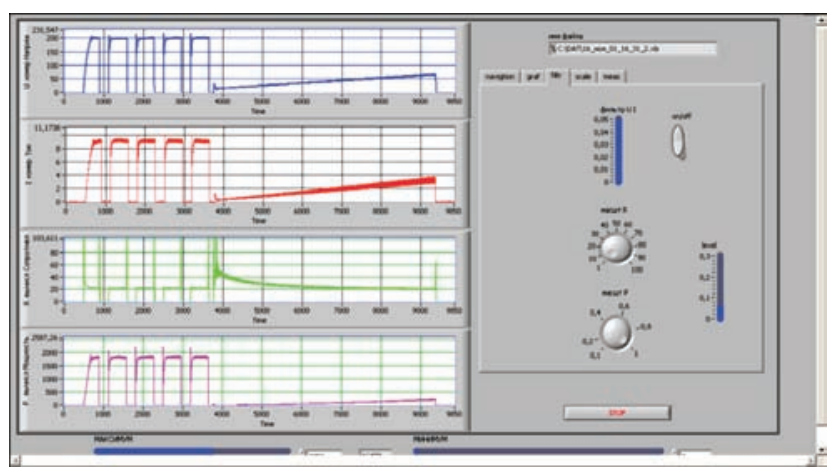

Figure 6. Appearance of the screen of data processing program required values with their storage in the form of .jpg and .xls type files. There is the capability of selection of the required scale and performance of program processing of the signal.

This complex was used to conduct more than 2500 studies on tissues of different type, in which optimum parameters and algorithms of operation in manual and automatic modes were determined, temperature of electrodes and tissue in the zone of electric current impact and variations of thickness of tissue with different structure at all the process stages were recorded. Results of these studies were further on used in preparation of recommendations and performance of actual surgical operations with application of the technology of live tissue welding both under laboratory and clinical conditions.

Results of experiments on welding the walls of pig stomach and small intestine are given below as an illustration. Influence of pulsed and continuous feed of voltage under the conditions corresponding to electric welding of biological tissues was studied. During the experiments, samples of the above tissues were placed between flat copper electrodes, compressed with specific pressure preset in the range from 2 up to $6 \mathrm{~N} / \mathrm{mm}^{2}$, and specific voltage in the range of $60-180 \mathrm{~V}$ at current frequency of $440 \mathrm{kHz}$ and pulse duration of $0.1-0.5 \mathrm{~s}$ was applied. After completion of experiments, tissue samples were sent to the morphological studies.

Conducted experiments showed that the impact of a single pulse of set duration and voltage value causes minor denaturation of collagen fibers subserously located on stomach walls, as well as partial damage of gastric mucosa. This is accompanied by development of slight swelling and expansion of connective septum of stomach wall muscle membrane (staining using hematoxylin-eosin was applied in all the cases) (Figure 7,a).

Coagulative necrosis of individual smooth muscle cells and fibroblasts was found in the muscle membrane, but contours of cells and their nuclei remained undamaged (Figure 7,b). 
Impact of two pulses of voltage, the same as in the first experiment, caused not partial, but complete destruction of the mucosa. Not just individual, but all the collagen and smooth muscular fibers in the point of electrode application also changed by the type of coagulative necrosis. Deformation of muscular fiber bundles across electrode plane and destruction of smooth muscular fibers was also noted in some points (Figure 8,a).

After application of nine voltage pulses formation of tight joints of collagen and smooth muscular fibers, having cell nuclei contours, was noted (Figure $8, b$ ).

After application of twenty voltage pulses a tight joint of stomach walls was formed as a result of coagulative necrosis of bundles of smooth muscular fibers and collagen fibers (Figure 8,c). Contours of cell nuclei are revealed in part of bundles smooth muscular fibers. In the thickness of the tissue contours of cell nuclei are found between the remnants of smooth muscular fibers. At this stage of electric welding the seam does not yet become uniform.

Further increase of the number of pulses up to 35 showed that in this case already a uniform, strong, thin electric welding seam was produced, which was formed by collagen and smooth muscular fibers (Figure 8,d).

Investigations showed the possibility of producing a uniform electric welding seam under the experimental conditions after application of twenty voltage pulses and further constant application of HF voltage for a fixed time. Here, the bundles of smooth muscu-

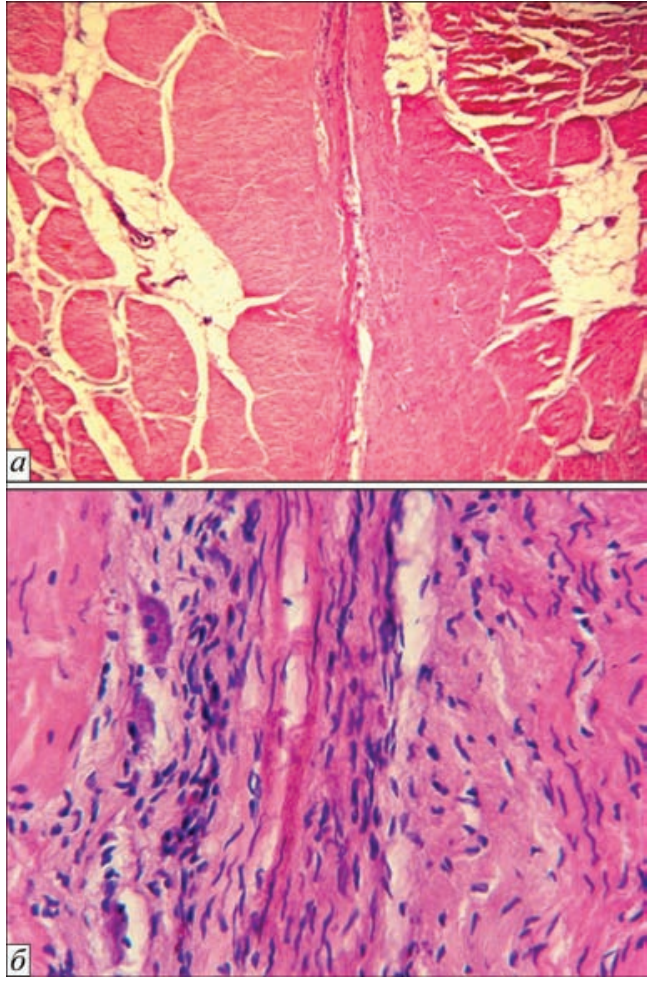

Figure 7. Structure of muscle membrane of stomach walls in the zone of application of isolated HF pulse: $a-\times 100 ; b-\times 400$

lar fibers in the seam are completely destroyed and coalesce with coagulated collagen fibers (Figure 9). Morphological signs of peripheral impact of electric welding current passage cover not more than $1 \mathrm{~mm}$ distance from the boundary of electrode application under experimental conditions (Figure 10).
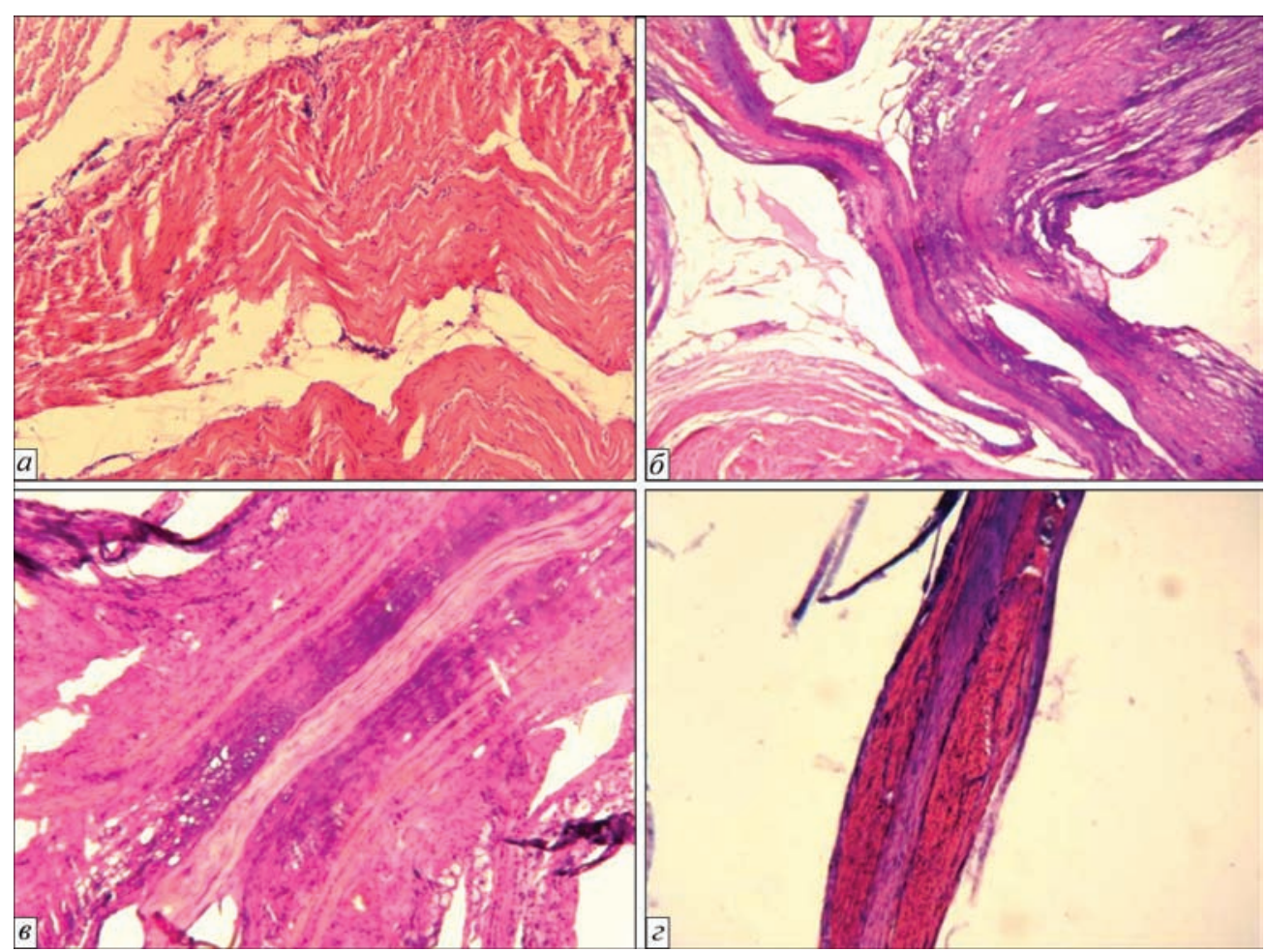

Figure 8. Structure of muscle membrane of stomach walls in the zone of application of two $(a)$, nine (b); twenty (c); thirty five (d) HF pulses: $a, b-\times 100 ; c-\times 400 ; d-\times 40$ 


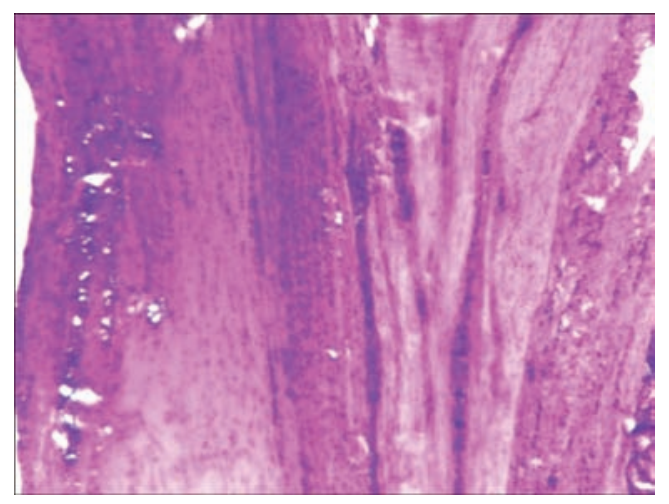

Figure 9. Uniform electric welding seam of two stomach walls after the impact of twenty HF pulses with subsequent application of HF voltage $(\times 400)$

Conducted studies confirmed that under the impact of a series of HF voltage pulses applied by a certain algorithm, a tight joint of biological tissues is formed - their electric welding seam. Necrosis areas are absent inside the seam. Such a seam is a new structure, which develops under the impact of electric current under optimum conditions that is exactly the purpose of electric welding.

\section{Conclusions}

1. Proposed all-purpose research complex allows quickly performing under laboratory conditions at minimum cost, studies of behaviour of biological tissues of various types under the impact of HF current on them at all the stages of the welding process.

2. Described research complex allows studying the influence of such design and process parameters, as electrode design and material, their compression forces, algorithms and modes of voltage application to the tissue on structural changes and process of welding of biological tissues. This complex allows determination of optimum modes and algorithms of welding various tissues both in the manual and automatic modes.

3. Results of performed studies can be recommended as basic ones at selection of process parameters during performance of surgical operations with application of the technology of live tissue welding both under laboratory and clinical conditions.

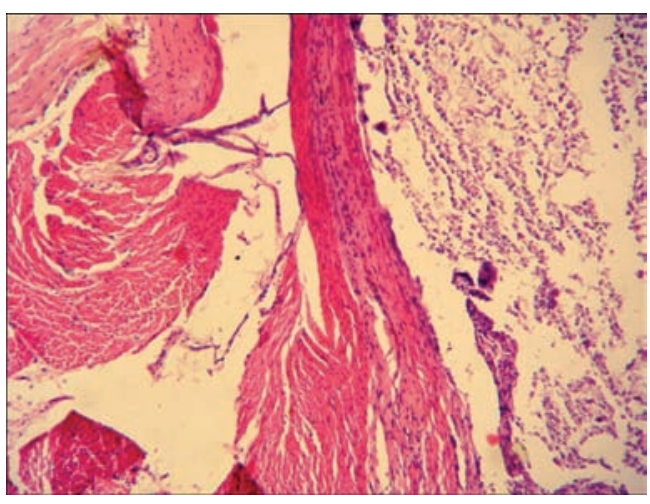

Figure 10. Indications of peripheral impact of electric welding voltage $(\times 100)$

1. (2009) Tissue-saving high-frequency electric welding surgery. In: Atlas. Ed. by B.E. Paton and O.I. Ivanova. Kiev: IAW.

2. (2013) Theory. Practice. Prospects. In: Proc. of $8^{\text {th }}$ Sci.-Pract. Conf. on Welding and Heat Treatment of Live Tissues. Ed. by G.S. Marinsky. Kiev: PWI.

3. (2014) Theory. Practice. Prospects. In: Proc. of $9^{\text {th }}$ Sci.-Pract. Conf. on Welding and Heat Treatment of Live Tissues. Ed. by G.S. Marinsky. Kiev: PWI.

4. (2015) Theory. Practice. Prospects. In: Proc. of $10^{\text {th }}$ Sci.Pract. Conf. on Welding and Heat Treatment of Live Tissues. Ed. by G.S. Marinsky. Kiev: PWI.

5. Bondar, G.V. (2011) Widening of indications for application of electric welding complex of soft tissues in oncosurgery. In: Proc. of $6^{\text {th }}$ Int. Seminar on Welding of Soft Live Tissues. Stateof-the-Art and Prospects of Development (Kiev, Ukraine, 2-3 December 2011). Kiev: PWI.

6. Makarov, A.V., Getman, V.G., Myasnikov, D.V. et al. (2006) Welding of pulmonary tissue - as a method of non-resection intervention because of spontaneous pneumothorax. Klinichna Khirurgiya, 7, 40-42.

7. Podpryatov, S.E., Gychka, S.G., Podpryatov, S.S. et al. (2008) Healing of interintestinal anastomoses and closing arteries by electric welding. Ibid., 11/12, 64.

8. Paton, B.E., Marinsky, G.S., Podpryatov, S.E. et al. High-frequency welding electrocoagulator EKVZ-300. Pat. 72577U Ukraine. Int. Cl. A 61 B 18/12. Fil. 24.01.2012. Publ. 27.08.2012.

9. Paton, B.E., Krivtsun, I.V., Marinsky, G.E. et al. (2013) Welding, cutting and heat treatment of live tissues. The Paton Welding J., 10/11, 142-153.

10. Paton, B.E., Tkachenko, V.A., Marinsky, G.S. et al. Method of joining of biological human and animal tissues using high-frequency current. Pat. 106513 Ukraine. Fil. 26.07.2012. Publ. 10.09.2014. 